\title{
An unusual case of worsening cellulitis: baboon syndrome or SDRIFE
}

\author{
Shane Fischbach, ${ }^{1}$ Natalie Hall, ${ }^{1}$ Sandeep Bains, ${ }^{1}$ Vijairam Selvaraj ${ }^{2}$
}

'Department of Medicine, Warren Alpert Medical School of Brown University, Providence, Rhode Island, USA

'Department of Medicine, Warren Alpert School ofMedicine, Brown

University, The Miriam Hospital, Providence, Rhode Island, USA

\section{Correspondence to} Dr Vijairam Selvaraj, vijairam.selvaraj@lifespan.org

Accepted 11 March 2018

\section{DESCRIPTION}

A 64-year-old woman with a history of HIV on Complera and peripheral vascular disease presented to the hospital with chills, progressively worsening bilateral leg pain and was admitted for bilateral cellulitis. She had been discharged from the hospital 2 months prior for right lower extremity cellulitis, which was treated with ceftriaxone. She has known allergies to doxycycline, vancomycin and penicillins, although the reaction to these drugs is unclear. Physical examination was remarkable for a shallow ulcer in the left lower extremity and two ulcers in the right lower extremity with irregular margins that were tender to palpation with minimal surrounding erythema, being treated with Medihoney. Laboratory workup was only significant for hyponatraemia of 130 and leucocytosis of 14000.

She was started on ceftriaxone and clindamycin for broad-spectrum antimicrobial coverage. On day 3 , there was significant erythema around the ulcers that extended proximally (figure 1). Ceftriaxone was discontinued and daptomycin was started. On day 4, she developed a morbilliform rash with erythematous macules that coalesced into patches on the bilateral axillae, upper chest, proximal arms, groin, buttocks and legs (figures 2, 3 and 4). On day 4 , infectious disease consultants recommended discontinuing daptomycin. On day 5, dermatology consultants recommended stopping all antibiotics

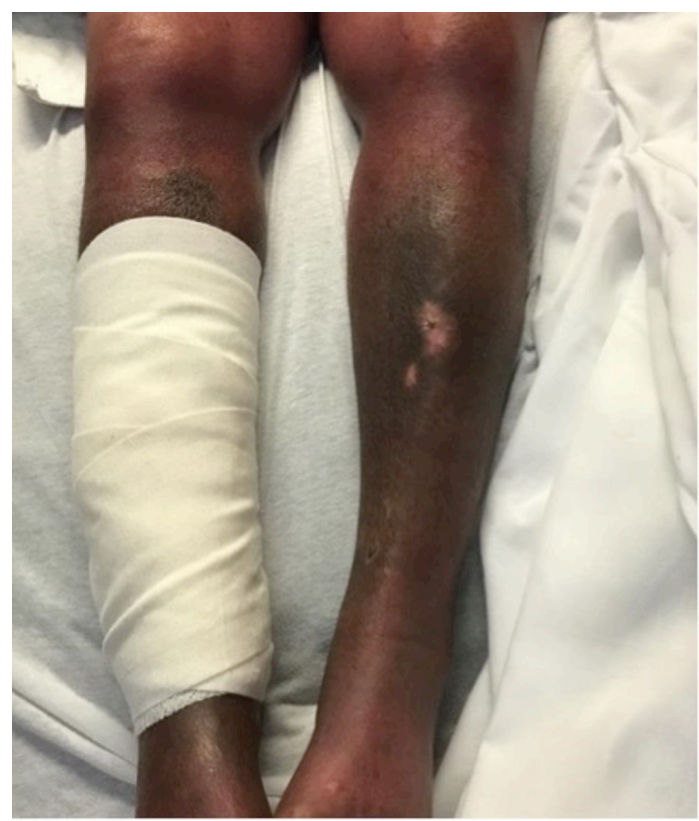

Figure 1 Erythema around the lower extremity ulcers that extended proximally to the groin, bilaterally.

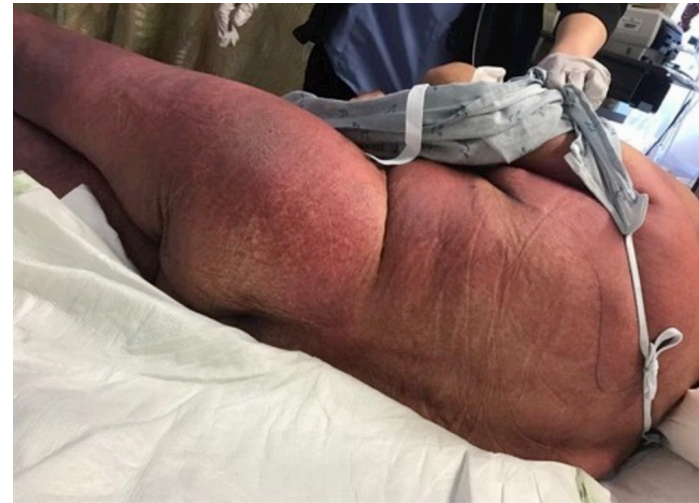

Figure 2 Morbilliform rash with erythematous macules that coalesced into patches on the buttocks, legs and groin.

and mentioned the presentation was consistent with symmetrical drug-related intertriginous and flexural exanthema (SDRIFE). There was no evidence of mucosal involvement or desquamation, nor were there dusky-appearing lesions, bullae or vesicles. She symptomatically improved with topical steroids within 1 week.

SDRIFE is a well-defined, erythematous rash that typically occurs in the skin folds in a symmetric distribution after systemic exposure to a drug such as penicillin. Onset is usually 5-14 days after starting the offending agent, although it can occur in 3-7 days if they have been exposed earlier. Commonly implicated drugs include penicillins, mercury and nickel along with chemotherapeutic drugs. In our

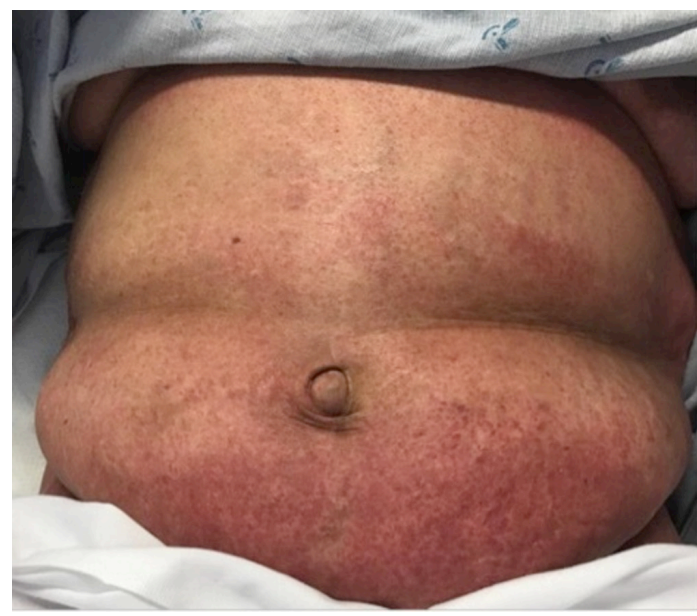

Figure 3 Morbilliform rash with erythematous macules that coalesced into patches on the buttocks, legs, upper chest, bilateral axillae and proximal arms. 


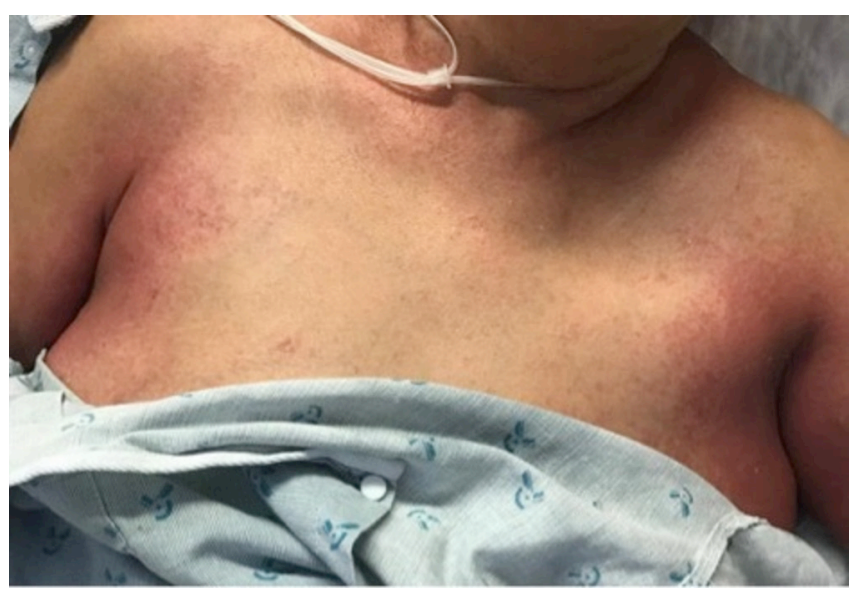

Figure 4 Morbilliform rash with erythematous macules that coalesced into patches on the buttocks and legs, a pattern consistent with symmetrical drug-related intertriginous and flexural exanthema.

case, the exact offending agent was difficult to identify. Prior use of Medihoney and no reported literature of systemic atopic reactions make it less likely to be the culprit. There have been prior case reports implicating cephalosporins ${ }^{1}$ and clindamycin ${ }^{2}$ that fit the timeline. There have been no previous reports implicating daptomycin as an offending agent, although in our case there was significant worsening of the rash following one dose. The mechanism is unknown although it may be related to a type IV sensitivity reaction. ${ }^{3}$ Treatment is usually withdrawal of offending antibiotics along with topical or parenteral steroids to provide symptomatic relief. There were no diagnostic procedures done to confirm the allergic reaction and the patient did

\section{Learning points}

- Symmetrical drug-related intertriginous and flexural exanthema (SDRIFE) is a symmetric rash in the skin folds caused by a sensitivity reaction to systemically administered drugs or food.

- SDRIFE treatment involves withdrawal of the offending agent and use of topical or parenteral steroids.

- In patients who appear to have worsening cellulitis resistant to the selected antibiotic treatment, consider adverse drug reactions such as SDRIFE secondary to antibiotics.

not follow up with dermatology as an outpatient, which is a limitation in our case.

Contributors VS was involved in writing the manuscript; NH and SF were involved in obtaining clinical data and SB was involved in revising the manuscript.

Funding There was no funding for this research from any funding agency in the public, commercial or not-for-profit sectors.

Competing interests None declared.

Patient consent Obtained.

Provenance and peer review Not commissioned; externally peer reviewed.

(C) BMJ Publishing Group Ltd (unless otherwise stated in the text of the article) 2018. All rights reserved. No commercial use is permitted unless otherwise expressly granted.

\section{REFERENCES}

1 Dhingra B, Grover C. Baboon syndrome. Indian Pediatr 2007;44:937.

2 Tan SC, Tan JW. Symmetrical drug-related intertriginous and flexural exanthema. Curr Opin Allergy Clin Immunol 2011;11:313-8

3 Morbilliform drug reaction. $2016 \mathrm{http}: / /$ www.dermnetnz.org/reactions/morbilliform.htm

Copyright 2018 BMJ Publishing Group. All rights reserved. For permission to reuse any of this content visit

http://group.bmj.com/group/rights-licensing/permissions.

BMJ Case Report Fellows may re-use this article for personal use and teaching without any further permission.

Become a Fellow of BMJ Case Reports today and you can:

- Submit as many cases as you like

- Enjoy fast sympathetic peer review and rapid publication of accepted articles

- Access all the published articles

Re-use any of the published material for personal use and teaching without further permission

For information on Institutional Fellowships contact consortiasales@bmjgroup.com

Visit casereports.bmj.com for more articles like this and to become a Fellow 